\title{
Evidências de poder expressas em projetos arquitetônicos do Hospital Santa Catarina $(1974-2002)^{\prime}$
}

\section{Evidence of power expressed in architectural projects of the Hospital Santa Catarina (1974-2002)}

\author{
Patrícia Draganov ${ }^{a}$ \\ (D) https://orcid.org/0000-0003-3764-8911 \\ E-mail: patricia.boverळunifesp.br \\ Maria Cristina Sanna ${ }^{b}$ \\ (D) https://orcid.org/0000-0002-5472-5408 \\ E-mail: mcsanna®uol.com.br \\ anniversidade Federal de São Paulo. Escola Paulista de \\ Enfermagem. Departamento de Administração de Serviços de \\ Enfermagem e Saúde. São Paulo, SP, Brasil.

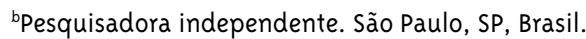

\section{Resumo}

A arquitetura hospitalar é um elemento disciplinador que contribui para a categorização, a classificação e a individualização dos atores sociais que compartilham esse espaço. Este estudo histórico analisou a trajetória da autoria dos projetos e do fluxo de pessoas, coisas e informação, além da disposição, da denominação e das dimensões dos compartimentos do Hospital Santa Catarina. Os achados foram interpretados à luz da literatura científica encontrada sobre o tema e do referencial teórico de Michel Foucault, o que permitiu compreender como se deram as disputas de poder por esses atores sociais. A enfermagem, um dos grupos presentes nesse espaço ao longo de todo o período estudado, ora ampliou ora teve reduzido o domínio sobre ele, pois ora a enfermagem foi destinada a esse espaço privativamente, ora foi deslocada para áreas onde a vigilância e a observação eram mais difíceis, ora passou a compartilhar espaços antes exclusivos. Essa dinâmica de disputa de poder impactou a qualidade da assistência prestada e as condições de trabalho dos profissionais de saúde.

Palavras-chave: Arquitetura Hospitalar; Legislação Hospitalar; Poder; Enfermagem; História.

\section{Correspondência}

Patricia Draganov

Universidade Federal de São Paulo. Escola Paulista de Enfermagem. Rua Napoleão de Barros, 754, 2 andar, sala 203. São Paulo, SP, Brasil. CEP $04023-900$.

1 A pesquisa cujos resultados são apresentados neste artigo contou com o auxílio financeiro da Coordenação de Aperfeiçoamento de Pessoal de Nível Superior (Capes). 


\section{Abstract}

Hospital architecture is a disciplinary element that contributes to the categorization, classification and individualization of social actors that share this space. This historical study analyzed the authorship trajectory of the projects, flow of people, things and information, in addition to the disposition, naming and dimensions of the compartments at the Hospital Santa Catarina. We used the academic literature on the matter as well as Michel Foucault's theoretical framework to interpret the results and understand the power disputes of these social actors. Nursing, one of the groups present in this space throughout the analyzed period, oscillated between increasing and decreasing control over the space. This occurs because their control was assigned privately at times, moved to areas where surveillance and observation were more difficult, or their previously confidential spaces started being shared. This power dispute dynamics affected the quality of care and the working conditions of the evaluated health professionals.

Keywords: Hospital Architecture; Hospital Legislation; Power; Nursing; History.

\section{Introdução}

A intersecção das ciências da arquitetura e da enfermagem, no que tange à organização do espaço físico hospitalar e à interação entre os atores sociais que nele disputam poder, é o foco deste estudo. Uma forma de compreender como as transformações do espaço hospitalar aconteceram é propiciada pela análise das normas legais para a construção e reforma dos estabelecimentos assistenciais de saúde (EAS). Considerando-se que a norma é a expressão do acordo social que tem como pano de fundo a disputa do poder entre os atores sociais envolvidos, resolveu-se primeiramente examinar as postulações legais sobre o espaço físico de EAS para compreender como ocorreu a disputa por esse poder ao longo do tempo. No Brasil, a criação de instrumentos legais para disciplinar a estrutura física do hospital moderno teve seu início em 1974, com a edição do documento intitulado Normas de construção e instalação do hospital geral(Brasil, 1974), depois sucedida, em 1977 , pela Portaria $\mathrm{n}^{0} 4 \mathrm{oo}$, com o documento Normas $e$ padrões de construção e instalação de serviços de saúde (Brasil, 1977). Em 1995, uma nova legislação, a Portaria do Ministério da Saúde (MS) nº 1.884/1994, substituiu a precedente, estabelecendo o manual Projetos físicos de estabelecimentos assistenciais de saúde(Brasil, 1994). Por fim, em 2002, foi promulgada a Resolução da Diretoria Colegiada (RDC) no 50 , da Agência Nacional de Vigilância Sanitária (Anvisa, 2002), ainda em vigor. Cabe observar que a dinâmica de produção de normas nesse período foi intensa, ponderando-se que tenham ocorrido conflitos sobre esse espaço.

A análise do espaço como representação do poder fica contudo limitada quando somente se analisa a legislação. O poder é complexo, denso e difuso (Foucault, 2012), sendo oportuno completar a discussão com o estudo de documentos em que as relações de disputa de poder no espaço hospitalar da época foram registradas. Para tanto, foi necessário selecionar uma instituição que tivesse experimentado intensas modificações espaciais registradas em documentos históricos e que aceitasse compartilhar essas fontes documentais. A instituição eleita para o estudo, denominada "modelo-referência", se localiza no centro do município de São Paulo/SP, 
é centenária, particular, de corpo clínico aberto e de origem católica, mantendo rico acervo de documentos, dentre os quais os desenhos arquitetônicos (Pastro, 2006). Houve transformações estruturais profundas e significativas na instituição em foco no período citado, incluindo a mudança do perfil de atendimento, do modelo de assistência, da estrutura organizacional e da arquitetura, entre outras. Assim, justifica-se sua eleição para o presente estudo por se tratar de um modelo ideal para vislumbrar as relações entre a norma e sua interpretação prática, permitindo apreciar a disputa de espaço e, portanto, da distribuição de poder entre os atores sociais que nele coabitaram, em especial a enfermagem.

Para esse grupamento profissional, esta pesquisa pode estimular reflexões sobre sua prática e seu posicionamento nesse campo de disputa, ou seja, "seus ganhos e suas perdas" nesse cenário, tão significativo para a saúde e para a doença, visto que o espaço físico também é disciplinado em função das relações entre os atores sociais, como defende Foucault (2012). Como principal responsável pela vigilância e pelo disciplinamento, a enfermagem se ocupava dessas ações mesmo antes da concepção do hospital moderno. Para os demais profissionais da saúde e gestores desse campo, o estudo pode indicar lugares de disputa e ensejar a realização de investigações que examinem como esses atores sociais se comportaram ao longo do tempo, quais influências sofreram e exerceram e por quê. 0 presente estudo também dilata e aprofunda o entendimento de paradigmas da arquitetura e testa a sua potencialidade para a compreensão do contemporâneo (Brandão, 2012).

Com isso, este estudo visa descrever e analisar as transformações do espaço físico hospitalar por meio da apreciação do confronto entre as normas de construção e reforma de EAS expressas nos projetos arquitetônicos do Hospital Santa Catarina, hospital paulistano considerado modelo-referência para esse estudo, executados de 1974 a 2002, com foco na disputa de espaço de poder entre os atores sociais que nele interagiram.

\section{Método}

0 projeto arquitetônico é definido como um documento/monumento (Le Goff, 1996), uma fonte de pesquisa capaz de informar e problematizar questões disciplinares e outras relativas à sociedade, à economia, à política, aos tipos de investimento imobiliário, à cultura e à técnica de um determinado período. Assim, analisando a produção arquitetônica sob vários prismas, pode-se construir uma leitura histórica complexa, capaz de lançar novas hipóteses, iluminando as fontes de pesquisa e contribuindo para outras interpretações de determinada época (Silva, 2014).

O Hospital Santa Catarina, considerado modeloreferência para este estudo, cedeu acesso a 1.407 projetos arquitetônicos datados de 1906 a 2015 salvos em formato JPEG e dispostos no programa Excel, o que permitiu a seleção dos projetos de 1974 a 2002, resultando em 14 projetos arquitetônicos analisados. A partir desse material, uma nova planilha foi construída com as seguintes variáveis: localização do projeto arquitetônico na planta física da instituição; descrição do número do pavimento e andar tipo; ano de confecção do projeto arquitetônico; e link para o arquivo com o respectivo desenho.

Para cada um dos 14 projetos arquitetônicos foi aplicada uma ficha analítica adaptada de Cellard (2008), contendo: (1) número de série que o documento recebeu (codificação); (2) data presente no projeto arquitetônico, para situá-lo no recorte temporal; (3) dados relativos ao contexto social, político e econômico no qual foi produzido o documento; (4) autoria - indicando os interesses do documento, suas razões e as daqueles a quem se dirige, se este fala em nome próprio ou de um grupo -, que pode ser localizada na assinatura presente no carimbo do projeto arquitetônico; (5) natureza do documento, tipo de desenho e o que ele retrata; (6) conceitos-chave e lógica interna, em que se descreveu fluxo, disposição, denominações, dimensões, entre outros; e (7) análise preliminar do documento, com dados sobre questões relativas às transformações do espaço físico, à norma legal que as regulava e às disputas por ele.

Depois que as fichas analíticas foram confeccionadas, os dados contidos em cada uma delas foram agrupados por pertinência e similaridade temática, resultando nas seguintes categorias de análise: (1) autoria dos projetos arquitetônicos; (2) fluxo e disposição; (3) denominação; e (4) dimensões dos compartimentos. Cada ficha analítica foi 
anexada à planilha Excel, junto ao seu respectivo projeto arquitetônico. Por fim, os achados foram descritos e interpretados à luz da literatura científica encontrada sobre o tema e do referencial teórico de Michel Foucault.

\section{Resultados e discussões: o espaço físico hospitalar e as relações de poder}

A instituição modelo-referência apresenta dez edificações, denominadas blocos, no terreno que a comporta. Os blocos são identificados por letras de
A a I, sendo a capela a única que não recebe letra para sua identificação. Os blocos compreendem as áreas de assistência e as áreas administrativas e de serviços de apoio. Os blocos A, B, C e F foram selecionados para este estudo e compõem as áreas de assistência e administração. Os blocos onde a assistência é prestada compõem-se de andar tipo, de unidades de internação, do pronto-atendimento (PA), das unidades de terapia intensiva, da maternidade, do centro cirúrgico e obstétrico e da central de materiais e esterilização. Os blocos citados podem ser visualizados, em destaque, no mapa de áreas que integra a Figura 1.

Figura I - Mapa de áreas, disposição dos blocos A, B, C e F da instituição modelo-referência, Hospital Santa Catarina, São Paulo, 2015



Fonte: Hospital Santa Catarina (1974-2002)

\section{Autoria}

Entre 1965 e 1977, os arquitetos Adolpho Rubio Morales e Fábio Kok de Sá Moreira, vencedores do concurso para a construção do edifício do Poder Legislativo Paulista na década de 1960, desenharam e executaram os projetos de reforma e ampliação do hospital modelo-referência. ${ }^{2}$ Em 1992, a empresa Bross \& Leitner Arquitetura e Consultoria, especializada em edificações de saúde, foi contratada para a reforma do bloco B. Em 1994, permaneceu contratada a empresa Leitner Arquitetura e
Consultoria, em nome de Elizabeth D'Angelo Leitner e de Eduardo Alexandre Soubhia, para regularizar os projetos de reforma das instalações destinadas à diretoria e das conexões entre os blocos. O engenheiro Eduardo Alexandre Soubhia também era gerente de engenharia da instituição estudada desde 1989, onde permaneceu até 2001. ${ }^{3}$ Em um dos projetos desse ano, observou-se a aposição da assinatura da Irmã Lia Maria, então diretora-geral da instituição, que o aprovou.

Entre 1995 e 1996 houve a conclusão do processo de reforma, culminando com o pavimento oito do

\footnotetext{
Segundo informações da homepage da MHA Engenharia. Disponível em: <https://bit.ly/39P2Y4q>. Acesso em: 11 maio 2018.

3 Segundo informações do currículo on-line de Eduardo Alexandre Soubhia no site LinkedIn. Disponível em: <https://bit.ly/3o1QLıe>. Acesso em: 11 maio 2018.
} 
bloco A e a instalação da diretoria no bloco industrial. Em 1999, projetos de ampliação e integração entre os prédios A, B e C, de autoria do engenheiro Armando Latuf, da MHA Engenharia de Projetos, foram realizados. ${ }^{4}$

Por fim, em 2001, o projeto de reforma do PA, de autoria exclusiva da própria instituição, fez crer que provavelmente o Serviço de Arquitetura e Engenharia tinha seu departamento na instituição nessa época, tal como atualmente, e passou a se responsabilizar integralmente por seus projetos. Esse último projeto, que começou a ser desenhado em 2001, apresentava assinaturas de aprovação, diferentemente dos anteriores, tendo destaque, por estar legível, a da enfermeira e então coordenadora administrativa do Centro de Imagens e Diagnósticos e PA, Luiza Papaleo, provavelmente em resposta às políticas públicas de saúde e às legislações que sustentam a prática profissional como a Lei do Exercício da Enfermagem (Brasil, 1986) -, que prescrevem essa participação.

Projetistas de empresas de destaque na área da construção civil e religiosos da instituição assinavam com exclusividade os projetos de reforma e construção desse EAS, até que em 2001 observouse a participação da equipe multiprofissional na aprovação dos projetos, o que incluía a enfermagem. Para Foucault (2012), a autoridade científica classifica e ordena o conhecimento acerca dos grupamentos humanos no espaço hospitalar e, durante 27 dos 28 anos estudados, representantes da Igreja Católica ordenaram, com exclusividade, a divisão dos espaços da instituição modelo-referência, embora tivessem deixado os espaços de assistência, como se verá a seguir.

Nos projetos arquitetônicos das décadas de 1970 a 1990, na área central do espaço das unidades onde era prestada a assistência, havia compartimentos designados para determinados grupamentos, como as irmãs. Para Foucault (2012), a existência de um ponto central define o local do exercício de poder e do registro do saber. Esse ponto central é um campo de visibilidade total, que permite o controle e a disciplinarização do espaço e das pessoas que nele circulam (Foucault, 2012). Esse achado indica que, nessas décadas, a autoridade religiosa nesse hospital ainda tinha seu espaço de poder para classificar, ordenar e vigiar.

As irmãs da caridade prestaram cuidados aos doentes durante muitos séculos mas, no final do século XVIII, com a medicalização do hospital, a saúde e os agentes que a promovem se profissionalizaram. Por conta dessa mudança, esse grupamento foi deixando paulatinamente a assistência e seus espaços de poder. Como exemplo disso, em 1890 registrou-se um desacordo entre a administração superior e as irmãs de caridade do Hospício Nacional de Alienados, berço da psiquiatria e da enfermagem moderna no Brasil, resultando na saída daquelas religiosas. Na verdade, essa dinâmica envolveu relações políticas, sociais e econômicas e, portanto, de poder (Oguisso; Schimidt, 2017).

\section{Componentes do projeto arquitetônico}

Em 1974, foi criado o Ministério da Previdência e Assistência Social, que centralizou e reforçou a dominância do modelo clínico assistencialcurativista de prestação de serviços de saúde (Braga; Paula, 1987). No mesmo ano foi publicado o texto das Normas de construção e instalação do hospital geral(Brasil, 1974). A referida norma assegurou que a programação, o projeto, a construção e a instalação de EAS favorecessem o atendimento eficiente, seguro e econômico no hospital geral. Essa norma apresentava as áreas do EAS com as denominações "postos", "consultórios" e "suítes”, entre outras, sem especificar detalhes sobre os profissionais que as ocupavam.

Em 1975 foi regulamentada a Lei $n^{0}$ 6.229, que criou o Sistema Nacional de Saúde, em que foram definidas as responsabilidades das várias instituições, cabendo à Previdência Social a assistência individual e curativa, enquanto os cuidados preventivos e de alcance coletivo ficaram sob a responsabilidade do Ministério da Saúde e das secretarias estaduais e municipais de saúde (Brasil, 1975). Nesse cenário entrou em vigor a Portaria $n^{\circ}$ 400/1977 (Brasil, 1977), mais específica que a norma de 1974 quanto à designação dos grupamentos

4 Segundo informações da homepage da empresa. Disponível em: 〈https://bit.ly/3iy7Tug>. Acesso em: 11 maio 2018. 
que ocupavam os compartimentos, dando grande destaque à enfermagem. Assim, observou-se, no hospital em foco, que a enfermagem, de acordo com a norma, pareceu ocupar espaços físicos definidos e obter reconhecimento de seu papel administrativo ("Sala para a chefia de enfermagem") e assistencial (“Unidade de enfermagem”), tendo essa ocupação se diferenciado em termos de localização e atuação.

Nessa época, o governo Geisel marcou o fim do "milagre econômico", cujos efeitos se fizeram sentir no setor saúde por meio da crise no padrão de prestação de serviços da rede pública e da previdência social. 0 quadro epidemiológico passou a evidenciar a coexistência de doenças crônicodegenerativas e de doenças infectocontagiosas, que passaram a assolar também as cidades (Braga; Paula, 1987). Em decorrência disso foram propostos programas nacionais de atendimento à saúde. Nessa época, havia investimento público no setor privado de saúde e, em consonância com esse fato, o hospital modelo-referência estava em franco crescimento, fato observado por meio dos projetos arquitetônicos estudados.

Quanto ao fluxo e à disposição, os desenhos observados na Figura 2, datados entre 1965 e 1977 , tinham seus pavimentos com compartimentos dispostos de forma oposta, ou seja, dispostos frente a frente, de forma que houvesse circulação central, denominada horizontal. A circulação vertical, ou seja, a comunicação com outros pavimentos, se dava por meio de escada e elevador, dispostos no centro do pavimento.

Quanto à denominação, nos projetos datados entre 1965 e 1977 as unidades de internação do bloco A tinham os seguintes compartimentos: suítes, salas de estar, sala da fisioterapia, sala da irmã junto com a sala de utilidades, sala do médico e posto, que também recebia a denominação de "posto de serviço" - esses três últimos em posição central. Além disso, ali estavam instalados a sala de curativos, o hall, a copa, o isolamento, as escadas, e os elevadores, distribuídos de forma a segregar a população em "público", "de serviço" e "médicos e pacientes", como se pode apreciar na Figura 2.

Quanto às dimensões, os projetos de 1965 a 1977 do bloco A tinham suítes com áreas de aproximadamente $12 \mathrm{~m}^{2}$, localizadas na periferia do andar, e dimensões iguais para os compartimentos centrais (salas da irmã e do médico). 0 posto era bem menor, com aproximadamente $6 \mathrm{~m}^{2}$, ou seja, reduzido à metade das dimensões dos primeiros compartimentos citados, mas contava com uma sala de serviço de $12 \mathrm{~m}^{2}$ a ele acoplada. Embora não tenha sido assim nomeada, a área onde a enfermagem organizava seu trabalho provavelmente era o posto e a sala de serviços que, somadas, resultavam em aproximadamente $18 \mathrm{~m}^{2}$. O posto seguia a recomendação da Portaria $n^{0}$ 400/1977, em vigor na época, porém a denominação do espaço não a seguia, ou seja, de acordo com a norma, esse local deveria ser nomeado como "posto de enfermagem" e não o foi, prenunciando assim a disputa do espaço. A sala da fisioterapia tinha $7 \mathrm{~m}^{2}$.

\section{Figura 2 - Fluxo e disposição dos compartimentos no andar tipo, Hospital Santa Catarina, São Paulo, 2015}



Fonte: Hospital Santa Catarina (1974-2002)

No período de 1965 a 1977 , o projeto do bloco A tinha suas enfermarias distribuídas de forma similar à proposta nightingaleana, mas considerando também os avanços arquitetônicos da época e a tendência de verticalização do 
hospital, visto que já se tinha, há algum tempo, o elevador e o sistema de calefação artificial instalados (Draganov; Sanna, 2017). Assim, parte do fluxo permanecia horizontal e os pavimentos tinham suas suítes e demais compartimentos distribuídos opostamente, com elementos de observação, vigilância e controle situados no centro dessa planta física, onde também se situava a circulação vertical por meio de elevadores e escadas, permitindo ainda que se observasse quem e o que adentrava e deixava o andar. As denominações de alguns compartimentos não correspondiam aos preconizados pela norma para construção e reforma de EAS de 1974, mas estavam em acordo com a norma de 1977, pois tinham identificação de grupamentos para alguns compartimentos, tais como a sala da irmã, a sala dos médicos e a sala da fisioterapia. A enfermagem e a figura do enfermeiro não se achavam nas denominações dos compartimentos nos projetos analisados dessa época, ou seja, nenhum espaço recebia a denominação "enfermeiro" ou "enfermagem”.

O nascimento do hospital, segundo Foucault (2012), foi marcado pela disciplinarização do espaço. Essa técnica de distribuição dos indivíduos por meio da inserção dos corpos em espaços individualizados, classificatórios e combinatórios é um tipo de relação de poder disciplinar associado ao controle do tempo, no sentido de exigir rapidez e eficácia, e ao controle minucioso das operações, ou seja, à vigilância permanente, possível também por meio da arquitetura, baseada no modelo do panóptico. Assim, foi a introdução da disciplina no espaço hospitalar o que o tornou medicalizado e terapêutico, e foi a intervenção arquitetônica no meio ambiente em que o hospital está alocado (ventilação, iluminação, posição, dimensão, fluxos, entre outros) o que permitiu vigiar, observar e controlar e, assim, disciplinar o espaço (Foucault, 2012).

A disposição do andar tipo, com princípios da enfermaria nigthingaleana, favorecia a assistência mas também a vigilância, a observação e o controle, incrementados pela posição central dos compartimentos de comando (irmãs, médicos, fisioterapeuta e enfermagem). Assim, os posicionamentos de alguns grupamentos superavam o objetivo assistencial, ou seja, seus ocupantes tinham visão estratégica de quem chegava ou saía do andar, o que abarcava o controle da informação, de materiais e dos profissionais que nele atuavam, além da clientela atendida.

Além disso, segundo Batista (2015) e Pires (2009), o modelo de administração da época se fundamentava nas teorias de Taylor e Fayol, valorizando o racionalismo e a produtividade obtidos com a disciplina e a hierarquização de tarefas e pessoas. Para o hospital e seus atores sociais, isso fez muito sentido, tanto no modo de trabalho escalonado e hierarquizado como na forma autocrática de comando, característica dessa época e da que imediatamente lhe sucedeu. Vale lembrar que o modelo de administração proposto à época era explícito ao criar as regras nas quais operavam a disputa e o exercício do poder, o que corroborava a proposta arquitetônica.

Observando por essa vertente, nessa época as irmãs dominavam o poder no hospital, lado a lado com os médicos. A fisioterapia tinha seu espaço nessa disputa e a enfermagem, que certamente ocupava a área do posto e serviços, ficava sitiada entre esses grupamentos dominantes, todos eles rodeados, é claro, pela figura do paciente, que ocupava a maior parte do espaço, mas que se localizava na periferia da unidade e era vigiado pelos profissionais.

Cumpre aqui entender qual era, de fato, a posição da "enfermagem sitiada" nesse cenário. A enfermagem adquiriu o status de profissão no Brasil no século XX e, embora o Parecer no 163/1972 do Conselho Federal de Educação determinasse o Currículo Mínimo dos Cursos de Enfermagem e Obstetrícia (Brasil, 1972), ainda estava por vir a fase de renovação do saber científico e do reconhecimento da profissão de enfermeiro em uma lei nova, que governasse significativamente seu exercício profissional e ensejasse o ensino de conteúdos sobre administração em sua formação (Brasil, 1994a). Conforme Foucault (2012), espaços são disputados somente entre aqueles com discurso e saber, e uma lei consistente, que garantisse especificidade ao exercício profissional, era um dos requisitos para atestar que o corpo de saber da enfermagem fosse socialmente reconhecido.

Por outro lado, se tem notícia de que o enfermeiro, nessa época, já ocupava cargos administrativos de alto escalão em algumas instituições e estava 
envolvido em decisões estratégicas e produzindo saber, como aconteceu com as Normas de construção e instalação do hospital geral (Brasil, 1974), que contou com a participação efetiva da enfermeira Clarice Della Torre Ferrarini, uma das profissionais da saúde a integrar a equipe que elaborou esse documento, composto de um rol de terminologias técnicas para favorecer a comunicação entre os atores que compunham o cenário da saúde naquela época (Sanna, 2002).

Assim, parece contraditório pensar que, por um lado, houve enfermeiros participando de decisões importantes no que se refere a espaços de saúde e a normas para construção de hospitais e, por outro, em momento algum esse profissional foi citado como dominando um saber e tampouco como usuário desses espaços na instituição estudada. Talvez por tratar-se de uma instituição privada, com dominância do modelo clínico assistencialcurativista e vinculada à Igreja Católica, que a fundou, a classe médica e a dos representantes religiosos tenha sido favorecida pela instituição. Com isso, provavelmente se explica o conflito da designação do espaço à luz da norma que o regulamentava, que declarava explicitamente que enfermeiros deveriam ter espaços privativos, mas que não foi o observado nos projetos arquitetônicos analisados. Enfim, nessa época, a enfermagem disputava espaços no hospital, mas ainda sem destaque e relevância, ou seja, ainda sem um corpo de saber materializado e que entrasse no jogo da disputa e dominância de poder. Na verdade, se encontrava cercada, observada e vigiada pela irmã e pelo médico, este último valorizado no contexto social, político e econômico da época por deter o poder da prescrição, que induzia ao consumo de produtos e serviços, o que, em um país ocidental e capitalista, fazia, e ainda faz, muito sentido.

No início dos anos 1980, no governo do presidente João Batista Figueiredo, a crise financeira no setor da saúde, que se sustentava até então no modelo assistencial-curativista, condenou esta escolha. Dessa forma, houve a proposta de um movimento sanitário para a reformulação do sistema de saúde, baseada na adoção do paradigma da história natural da doença e, com ele, a valorização do modelo de priorização da atenção primária, seguida da prevenção secundária e terciária, passando a preconizar a necessidade de investimentos na promoção da saúde e proteção específica, que possibilitaria a redução de custos (Teixeira, 1989).

Em 1983 entrou em vigor a Resolução da Comissão Interministerial de Planejamento e Coordenação (Ciplan) no 3/1981 e, com ela, prevaleceu a manutenção dos espaços destinados à enfermagem, com maior detalhamento desses serviços e ênfase no investimento no pessoal de apoio e na destinação de espaço para acomodação de pessoal para realizar os serviços de enfermagem com maior qualidade e segurança (Brasil, 1981). A enfermeira e os demais profissionais da enfermagem passaram então a disputar o espaço dito privativo do posto com o profissional médico. Já as atividades administrativas foram alocadas num único setor administrativo.

Nessa mesma década, profissionais da saúde preocupados com a saúde pública e com as questões relacionadas à prática direcionaram suas pesquisas científicas de modo a esclarecer suas modalidades de trabalho e suas articulações com a realidade social e seu desenvolvimento histórico. Na enfermagem, as pesquisas cresceram consideravelmente nessa época (Vietta et al., 1996), focando também a autonomia da profissão, a conquista do mercado pela promulgação da legislação do exercício profissional entre 1986 e 1987 - atendendo às reivindicações dos direitos da categoria e seus interesses - e o controle da vida profissional e de suas circunstâncias por meio dos conselhos Federal e Regional de Enfermagem (Paiva; Teixeira, 2014).

Com a vitória da Aliança Democrática e a eleição do presidente Tancredo Neves, que morreu por doença e infecção hospitalar logo após assumir o cargo e foi substituído pelo vice José Sarney, teve início a Nova República. Esse processo transicional da política repercutiu na saúde e, em 1986, o Ministério da Saúde convocou a VIII Conferência Nacional da Saúde (CNS) com a temática "Direito à Saúde", que propôs a elaboração da Reforma Sanitária e a criação do Sistema Único de Saúde (SUS), tendo como diretrizes a universalidade, a integralidade das ações e a participação social, além de ampliar o conceito de saúde, colocando-o como um direito dos cidadãos e um dever do Estado (Paiva; Teixeira, 2014). 
O processo de mobilização da sociedade, presente na VIII CNS, teve continuidade na elaboração da nova Constituição democrática e culminou na aprovação de um capítulo inédito que versava sobre a saúde - o direito universal à saúde, a saúde como um dever do Estado e a constituição do SUS, integrando todos os serviços públicos em uma rede, além da participação do setor privado no SUS de forma complementar (Escorel, 2008). Apesar dos avanços alcançados, permaneceu intocável o paradigma do modelo assistencial-curativista e, portanto, da maior relevância da figura do médico.

Em 1989, no governo do presidente Fernando Collor de Mello e, posteriormente, no seu impeachment, a oferta de serviços de saúde era altamente discriminatória e fragmentada, seletiva para os diferentes cidadãos segundo a sua inserção social e fixada na atenção médica, sendo evidente, após nove vetos de Collor à Lei $n^{0} 8.080$, o processo para o impedimento do avanço da implementação do SUS. Na área da saúde, o caos se instalava com brutal redução dos recursos de custeio e uma completa paralisação nos investimentos em manutenção e ampliação da rede de serviços (Paiva; Teixeira, 2014).

O panorama social, político e econômico da época era bastante instável e propício à mudança de paradigma. No entanto, talvez em consequência de um contexto social crítico e inseguro, de 1977 a 1992 não houve mudanças físicas significativas nos espaços da enfermagem no hospital estudado. Entretanto, a instituição citada se consagrava na área da saúde materno-infantil, pois nela haviam sido feitos os procedimentos para a concepção do primeiro bebê de proveta do Brasil (Pereira, 2011).

Finalmente, na década de 1990, o SUS passou a ser operacionalizado a partir das leis orgânicas da saúde (Brasil, 1990a, 1990b). A contraposição ao modelo de saúde praticado na época trouxe morosidade ao processo de ampliação do SUS, que seguiu com a expansão da rede ambulatorial em todo o país com a criação das unidades básicas de saúde (UBS), ambulatórios regionais, hospitais secundários e terciários, e a implementação do Programa de Saúde da Família, com ênfase na multidisciplinaridade e na atenção primária (Bertolozzi; Greco, 1996). Embora essas mudanças tenham marcado mais os EAS destinados à assistência primária, sua influência se estendeu também ao ambiente hospitalar.
No que se refere aos projetos arquitetônicos estudados, especificamente sobre o fluxo e a disposição, um projeto de reforma aprovado em 1992 no bloco B, que comportava leitos de enfermaria, incorporou ao posto de serviço um espaço para relatório médico. Nele, a sala da irmã foi abolida e se desenhou uma sala para a chefia de enfermagem como orientava a lei, porém em posição desfavorável para a observação, vigilância e controle do andar tipo, pois se localizava atrás da caixa da escada, como pode ser apreciado na Figura 3.

\section{Figura 3 - Posto com relatório médico e posicionamento da sala da chefia de enfermagem, Hospital Santa Catarina, São Paulo, 2015}
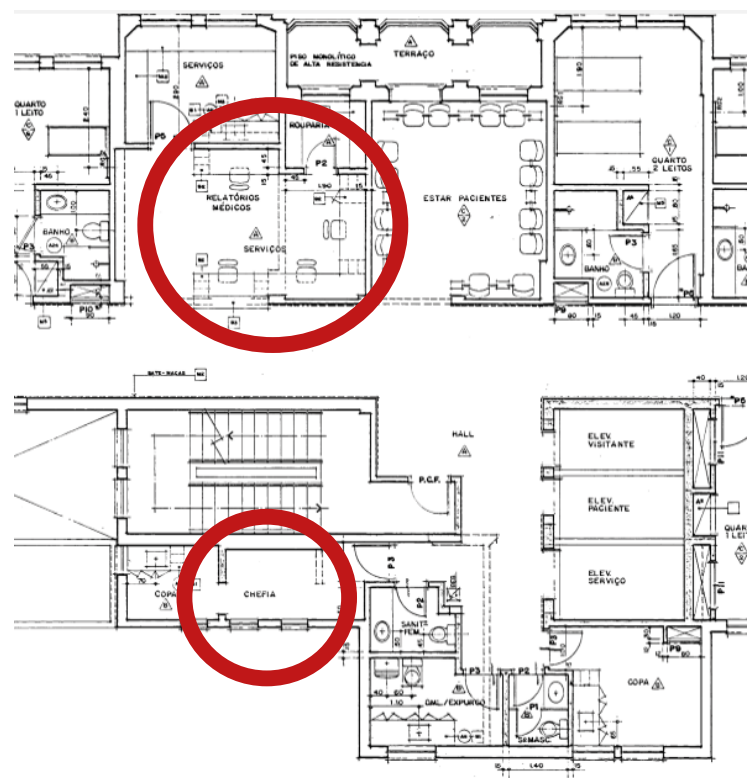

Fonte: Hospital Santa Catarina (1974-2002)

Em 1992, observou-se que no bloco B houve transformação de parte das enfermarias em suítes e vários novos serviços de apoio, atendendo ao novo modelo assistencial. Quanto às dimensões desses compartimentos, em 1992, no projeto de reforma no bloco B, o espaço para relatório médico no posto era de $1,2 \mathrm{~m}^{2}$, a sala da chefia tinha cerca de $3,4 \mathrm{~m}^{2}$ e não havia denominação desse espaço como sala privativa do enfermeiro, como recomendava a Resolução da Ciplan $n^{0} 3 / 1980$.

A enfermagem, ainda oculta nesses desenhos, já funcionava sob regulação da lei do exercício 
profissional da enfermagem (Lei no $7 \cdot 498 / 1986$ ), reconhecendo, com isso, a existência de um corpo de saber correspondente a esse grupamento de profissionais. A respectiva legislação considera, em seu artigo 11, que "o enfermeiro exerce todas as atividades de enfermagem, cabendo-lhe: [...] II - como integrante da equipe de saúde: [...] d) participação em projetos de construção ou reforma de unidades de internação" (Brasil, 1986). Assim, defende-se que o instrumento legal teoricamente potencializou a enunciação da enfermagem a respeito do espaço físico hospitalar, mas o reposicionamento e a interação dos atores sociais provocou a alteração do uso dos espaços na prática, inclusive daqueles que antes cabiam exclusivamente à enfermagem, ou seja, ao mesmo tempo que ela conquistava um novo espaço administrativo na área de assistência (chefia), perdia o espaço, antes exclusivo do posto, para o médico (relatório médico no posto). Esse movimento espacial configurou claramente o jogo dinâmico de disputa de poder, indicando a lei como um instrumento frágil de garantia de conquistas, enquanto a arquitetura mostrava-se um instrumento potente.

Dois anos depois, em 1994, os projetos arquitetônicos, no que se referia ao fluxo e à disposição, tinham similaridade com os projetos do andar-tipo do bloco B de 1992. Em 1994 também foi aprovado o projeto de reforma das instalações da diretoria, situada então no bloco F, em que uma rampa projetada facilitaria o processo administrativo, assegurando a conexão com o bloco A e permitindo o acesso desse serviço aos espaços de cuidar, observar, vigiar e controlar, conforme a Figura 4. As instalações destinadas à diretoria tinham uma planta física em forma de quadrado, com fluxo central e compartimentos opostos destinados a salas de expediente administrativo, recepção com espera, hall, sala de arquivo, copa, almoxarifado, sala de reunião, sala de supervisão médica, sala da superintendência administrativa, sala da diretoria clínica, sala de residência, depósito e sala de diretoria financeira. Quanto às dimensões, não havia elemento comparativo de metragem, pois a enfermagem não foi mencionada como usuária ou detentora de locus próprio nesse espaço, estando excluída das decisões estratégicas.
Figura 4 - Compartimentos da diretoria e acesso para o bloco A, Hospital Santa Catarina, São Paulo, 2015

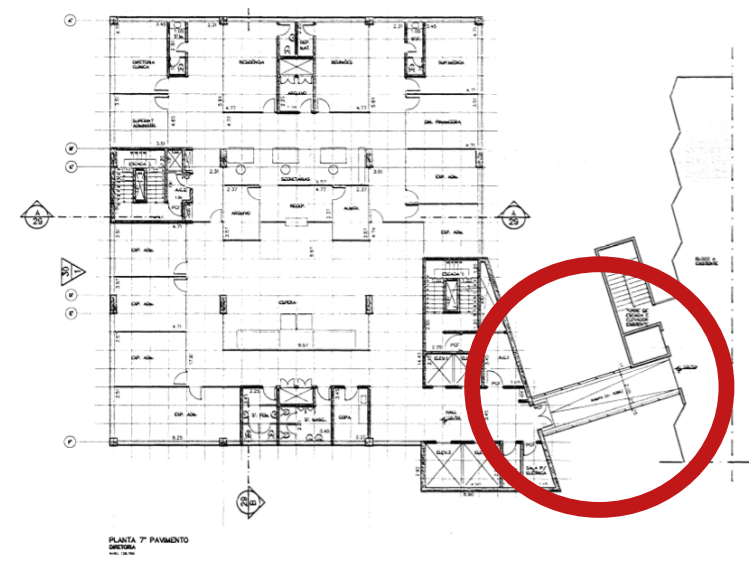

Fonte: Hospital Santa Catarina (1974-2002)

Em 1995, profundas alterações vieram a compor a nova proposta de normatização de espaços físicos de EAS, denominada Projetos Físicos de EAS (Brasil, 1994b). Os espaços físicos destinados à enfermagem, no que se convencionou normativamente chamar de posto de enfermagem, permaneceram com a metragem sugerida na norma anterior; porém, esse compartimento sofreu alteração importante e significativa nessa norma no que se refere ao seu conceito, que passou a ser compreendido, desse momento em diante, como ambiente destinado "à Enfermagem e/ou médicos para a execução de atividades técnicas e administrativas”, ou seja, o espaço deveria ser obrigatoriamente compartilhado e não mais destinado ao uso predominantemente da enfermagem. Nessa norma também citou-se pela primeira vez a sala para consulta de enfermagem e os consultórios, que antes recebiam a designação "médicos", passaram a ser designados como indiferenciados, reforçando assim a participação da equipe multiprofissional no atendimento à saúde em EAS.

Em conformidade com a norma em vigor na época, o projeto de 1995 apresentava elementos novos, tais como a secretaria de enfermagem, a sala da obstetriz - que se tornou "plantão obstetriz" -, a copa, o setor de informações e a sala de reanimação, que teve agregada um lactário. Com relação às dimensões, houve acréscimo de um posto de serviço com $9,6 \mathrm{~m}^{2}$, contando a unidade com dois postos; 
da secretaria de enfermagem, com aproximadamente $7 \mathrm{~m}^{2}$; da sala da obstetriz, com aproximadamente 13 $\mathrm{m}^{2}$; do setor de informações, com 3 $\mathrm{m}^{2}$; e da sala de reanimação, o que permitiu a instalação do lactário, com $3 \mathrm{~m}^{2}$, atendendo à demanda da assistência prestada nesse local.

Os ganhos de espaço e o posicionamento e elementos arquitetônicos novos - como a sala da obstetriz em posição central e a localização da secretaria da enfermagem, com a figura inédita do escriturário - indicaram valorização dos processos administrativos e financeiros ligados ao enfermeiro, observando-se inequívoca marca de conquista de espaço e de poder, o que acirrou novas disputas.

Para Foucault (2012), o hospital é um local de confronto, de separação entre os que têm poder e os que não o têm, gerando processos dinâmicos de disputa. Quando a enfermagem começou a se sobressair no espaço hospitalar por meio da sala de chefia, da secretaria da enfermagem e da sala da obstetriz em posição central, a chefia foi conduzida a um local que lhe impedia a observação, a vigilância e o controle, ou seja, atrás da caixa da escada, e o espaço privilegiado do posto, que era exclusivo da enfermagem, viu-se "invadido" pelo médico, que ganhou novo posicionamento que lhe permitiu vigiar e controlar o grupamento da enfermagem dentro do espaço em que ela estava, até então, operando exclusivamente. Em contrapartida, a Lei Orgânica da Saúde também condicionou o ambiente de disputa, valorizando a equipe multiprofissional. Para que um grupamento se mantenha dominante e se perpetue nessa condição, deve se ter um conjunto de táticas eficazes e sistemáticas, que funcionam sustentando grandes estratégias de cunho político, econômico e social. O domínio envolve força de produção de ideologia, ou saberes, e o saber disciplina as relações entre os atores sociais. Sempre que essa força dominante se vê ameaçada, ela faz manobras para expandir e reconquistar espaços; assim, se entende que a disputa de poder é dinâmica, pois ela nunca cessa. Por fim, registre-se que, para Foucault (2012), a arte de governar é a arte de exercer o poder segundo o modelo da economia, o que fica patente nas transformações ocorridas no hospital estudado.

Em 1999, uma modificação interessante de disposição e fluxo, como pode ser vislumbrado na
Figura 5, ocorreu na diretoria, que foi transferida para o bloco A e agregou o departamento de enfermagem, que se situava em frente à diretoria geral; porém, diferente das outras diretorias, sua denominação não atendia ao padrão das demais e não possuía secretaria própria. Os mobiliários lembravam uma de sala de reunião (uma mesa com 12 cadeiras), diferente das demais diretorias, como se pode apreciar na Figura 5 . Nos $8^{\circ}$ e $9^{\circ}$ andares, o vestiário médico passou a servir também aos enfermeiros, e o posto passou a ter a designação de "comando".

\section{Figura 5 - Departamento de Enfermagem na área da Diretoria, Hospital Santa Catarina, São Paulo, 2015}



Fonte: Hospital Santa Catarina (1974-2002)

Sobre dimensões, os projetos de 1999 incluíram salas para escriturários com $12 \mathrm{~m}^{2}$, e nele o enfermeiro ganhou espaço no vestiário médico, que tinha $7 \mathrm{~m}^{2}$. O departamento de enfermagem, situado na diretoria, tinha $28 \mathrm{~m}^{2}$, mesma medida da sala da diretoria geral e da sala de conforto médico, que eram as maiores. Houve decréscimo importante no espaço de suítes de internação nos pavimentos para acomodar o centro obstétrico, que foi ampliado.

Muitas devem ter sido as razões para tantas modificações, como a enfermagem, incorporada ao setor administrativo sem ostentar o título de diretoria e a consagração na administração dos serviços de enfermagem, mas é razoável supor que uma delas foi colocar-se em consonância com a norma legal. 
Para Foucault (2012), o que torna o poder forte passa a ser aquilo pelo qual ele é atacado. A ideia de que o poder vacila é falsa porque ele pode recuar, se deslocar e investir em outros lugares, podendo-se continuar a observar a disputa na nova disposição estratégica das peças. Assim, quando a enfermagem se deslocou e passou a ocupar espaços antes destinados a outros grupamentos, como a administração das unidades assistenciais, ou quando ela passou a ser denominada como proprietária do espaço, os grupamentos que detinham o poder se reposicionaram, se infiltrando nos espaços da enfermagem ou a reposicionando em locais ou com mobiliários nada estratégicos.

A enfermagem, de certa forma, aceitou essa movimentação e submeteu-se a ela, talvez em favor do movimento pela equidade multiprofissional e, também, como decorrente de sua história, em que se observa o antagonismo entre a identidade emergente dos aspectos sociais e religiosos, traduzidos em ideal abnegado que serve ao estado e ao médico, evidenciando a enfermagem como um corpo dócil e disciplinado, e o que de fato a enfermagem é, ou seja, um corpo de saber com competências assistenciais, administrativas, políticas, de ensino e de pesquisa que o tornam um profissional completo para conduzir qualquer cenário de saúde.

Para Foucault (2012), a identidade de um grupamento é produto de relações de poder, das táticas e estratégias utilizadas e da relação de forças que reprimem ou oprimem, o que envolve o recurso do abuso da soberania. Portanto, houve um jogo de luta e submissão, no qual se submeteu aquele que tinha a estratégia mais frágil, ou seja, a estratégia em que menos se encaixou a demanda social, política e econômica do Estado.

Em 1999, foi criada a Anvisa, por meio da Lei $n^{0}$ 9.782/1999 e do progresso da implantação do SUS e das demais agências reguladoras (Brasil, 1999). Assim sendo, a proposição de normas de projetos arquitetônicos e a rede física de assistência à saúde estariam sob sua regulação e fiscalização. Para atender a essa necessidade, em 2000 foi promovido um estudo pela Gerência Geral de Tecnologia em Serviços de Saúde da Anvisa, que viria posteriormente a se consolidar na RDC $\mathrm{n}^{0}$ 50/2002, no qual fluxo e dimensionamento de compartimentos receberam especial atenção. Quase que concomitantemente, no hospital modeloreferência estudado, em 2001 deu-se início ao projeto de reforma do PA adulto e pediátrico no bloco C. O fluxo e o dimensionamento eram os destaques do projeto, com o objetivo de favorecer o atendimento ao cliente pelos profissionais, compondo-se de compartimentos típicos dessa área, provavelmente se antecipando ao que determinariam as diretrizes da RDC no 50/2002, em discussão à época.

O PA infantil seguia o fluxo: entrada e recepção, espera, sanitários, fraldário, tesouraria e triagem/ observação infantil, reidratação oral, inaloterapia, emergência infantil, posto e três consultórios infantis. O PA adulto continha: entrada adulto, triagem, tesouraria, recepção - compartilhada com o PA infantil -, duas salas de pequenas cirurgias, sala de gesso, sala de sutura, sala de ressuscitação adultos e infantil, copa, depósito de material de limpeza, expurgo, medicação, rouparia, três postos, farmácia, estar, plantão médico, repouso para adultos, isolamento, inalação e três consultórios adulto. O projeto arquitetônico focava compartimentos para a prestação dos cuidados, suas respectivas dimensões e fluxos, atendendo ao disposto na norma de 1995 e presentes na RDC no 50/2002, que estava sendo concluída nessa época. 0 projeto do PA focava o conforto e bem-estar do paciente, com fluxos e compartimentos que dividiam o processo assistencial por demanda e risco.

Em 21 de fevereiro de 2002, foi publicada a Portaria GM/MS n ${ }^{0} 554$, entrando em vigor a RDC $n^{0}$ 50/2002 (Anvisa, 2002), que abrangia a boa estética hospitalar e focava a qualidade da edificação, em resposta às expectativas dos usuários, e ainda, atendia à Constituição Federal, à Lei Orgânica da Saúde e às Normas Brasileiras da Associação Brasileira de Normas Técnicas (Limeira, 2006).

Essa norma privilegiava o usuário, o empoderando, ou seja, um novo grupamento despontava na disputa do poder, apoiado pela facilidade de acesso à literatura científica da área da saúde e seu respectivo “dialeto" e pelas legislações que apoiavam a participação popular em gestão em saúde e o direito do consumidor. A equipe multiprofissional também recebeu o apoio dessa norma, fundamentada na legislação vigente que a subsidia, mas, como já 
dito antes, a norma é frágil perante as relações no campo de disputa.

Assim, o fato é que o modelo médico assistencialcurativista e hospitalocêntrico persistiu na sociedade brasileira, mesmo diante de uma proposta que privilegiava a assistência primária e o protagonismo do usuário e da equipe multiprofissional. Várias questões políticas, econômicas e sociais explicam a persistência desse paradigma, que gerou e gera consequências na qualidade da assistência prestada, nas condições de trabalho dos profissionais de saúde e na vida dos brasileiros e, a organização físico-espacial dos EAS expressa essa conformação. Para Foucault (2012), os instrumentos legais não são suficientes para provocar um deslocamento de poder; para efetivamente isso acontecer, é preciso muito mais: o campo onde a disputa se dá. Como se pode ver nos resultados deste estudo, o filósofo tinha razão.

\section{Considerações finais}

O estudo sobre a instituição em foco revelou as mudanças que foram incorporadas no edifício hospitalar antes e após a promulgação das normas que disciplinaram o seu uso à época, reforçando a afirmação de que a norma é o resultado de um “acordo" que a antecede. A norma, porém, é apenas um balizador e, por esse motivo, nem sempre ela foi seguida à risca. Houve reorganização do espaço em função das relações entre os atores sociais que o habitavam, motivadas pelo contexto social, político e econômico em que a instituição se inseria e pelas disputas que esses atores sociais e suas corporações travaram no meio da saúde.

As primeiras normas garantiam os espaços privativos da enfermagem, principalmente quando o exercício profissional da enfermagem teve o suporte de uma lei mais estruturada, como a promulgada em 1986. Posteriormente, com as leis orgânicas da saúde e a valorização da equipe multiprofissional, os espaços tornaram-se, teoricamente, de propriedade indiferenciada.

A enfermagem comportou-se, ao longo do período estudado, ora ampliando, ora reduzindo seus espaços de domínio, de certa forma mantendo-se perene. Sempre que algum espaço lhe era destinado privativamente, posteriormente observava-se o deslocamento desse espaço para áreas desprivilegiadas para o exercício da vigilância e observação, ou esses espaços eram invadidos e cercados pelo grupamento religioso e médico, o que gerava novas disputas e novas conquistas.

No hospital, a enfermagem sempre circulou nos espaços de assistência (a que se destina a maior metragem) mais que qualquer outro profissional ao longo da história, mas, por outro lado, não deteve o poder terapêutico que nele se exerceu, como aconteceu com o médico. Portanto, o saber médico incorpora questões econômicas e políticas, abrangendo uma esfera mais complexa que a estrutura hospitalar e se estende à estrutura cultural da sociedade, por isso, esta segue lhe destinando espaços privilegiados, o que estimula disputas acirradas entre esses dois grupamentos. A enfermagem, por sua vez, enfrenta esse cenário como pode, construindo sua história a partir das decisões estratégicas que esse seguimento social escolhe para se posicionar, no cenário dos EAS.

\section{Referências}

\section{ANVISA - AGÊNCIA NACIONAL DE VIGILÂNCIA}

SANITÁRIA. Resolução de Diretoria Colegiada $n^{\circ}{ }_{50}$, de 21 de fevereiro de 2002. Dispõe sobre regulamento técnico para planejamento, programação, elaboração e avaliação de projetos físicos de estabelecimentos assistenciais de saúde. Diário Oficial da União, Brasília, DF, 20 mar. 2002. Seção 1, p. 39.

BATISTA, F. R. B. Um ordena, outro obedece: o poder disciplinar no discurso das teorias clássicas da administração. Redis: Revista de Estudos do Discurso, São Paulo, n. 4, p. 11-38, 2015.

BERTOLOZZI, M. R.; GRECO, R. M. Health politics in Brasil: historical review and perspectives. Revista da Escola de Enfermagem da USP, São Paulo, v. 30, n. 3, p. 380-398, 1996.

BRAGA, J. C. S.; PAULA, S. G. Saúde e previdência: estudos de política social. São Paulo: Hucitec; Rio de Janeiro: Cebes, 1987.

BRANDÃO, C. A. L. Por que estudar história da arquitetura? Pós: Revista do Programa de PósGraduação em Arquitetura e Urbanismo da FAU-USP, São Paulo, v. 19, n. 32, p. 26-36, 2012. 
BRASIL. Ministério de Educação e Cultura. Parecer $n^{0} 163$, de 28 de janeiro de 1972. Fixa os mínimos de conteúdo e duração do curso de graduação em enfermagem e obstetrícia. Revista Brasileira de Enfermagem, Brasília, DF, v. 25, n. 1-2, p. 153-158, 1972.

BRASIL. Ministério da Saúde. Normas de construção e instalação do hospital geral. Brasília, DF, 1974.

BRASIL. Lei no 6.229, de 17 de julho de 1975 . Dispõe sobre a organização do Sistema Nacional de Saúde. Diário Oficial da União, Brasília, DF, 17 jul. 1975.

BRASIL. Ministério da Saúde. Normas e padrões de construção e instalação de serviços de saúde. Brasília, DF, 1977.

BRASIL. Ministério da Saúde; Ministério da Previdência e Assistência Social. Comissão Interministerial de Planejamento e Coordenação. Resolução Ciplan n ${ }^{0}$ 3, de 25 de março de 1981. Aprova as Normas para a Adequação e Expansão da Rede de Atenção à Saúde nas Unidades Federadas. Instituto Nacional de Assistência Médica da Previdência Social, Brasília, DF, 8 jul. 1981.

BRASIL. Lei ${ }^{0} 7 \cdot 498$, de 25 de junho de 1986. Dispõe sobre a regulamentação do exercício da enfermagem e dá outras providências. Diário Oficial da União, Brasília, DF, 26 jun. 1986.

p. 9273. Disponível em: <https://bit.ly/2YoF7ZO>. Acesso em: 11 maio 2018.

BRASIL. Lei n ${ }^{8} .080$, de 19 de setembro de 1990. Dispõe sobre as condições para a promoção, proteção e recuperação da saúde, a organização e o funcionamento dos serviços correspondentes e dá outras providências. Diário Oficial da União, Brasília, DF, 20 set. 199oa.

BRASIL. Lei no 8.142, de 28 de dezembro de 1990. Dispõe sobre a participação da comunidade na gestão do Sistema Único de Saúde (SUS) e sobre as transferências intergovernamentais de recursos financeiros na área da saúde e dá outras providências. Diário Oficial da União, Brasília, DF, 31 dez. 199ob.
BRASIL. Ministério da Saúde. Projetos físicos de estabelecimentos assistenciais de saúde. Brasília, DF, 1994a.

BRASIL. Ministério de Educação e Cultura. Conselho Federal de Educação. Parecer n ${ }^{0}$ 314, de 6 de abril de 1994. Currículo mínimo para o curso de enfermagem. Diário Oficial da União, Brasília, DF, 28 nov. 1994b.

BRASIL. Lei nº 9.782, de 26 de janeiro de 1999.

Define o Sistema Nacional de Vigilância Sanitária, cria a Agência Nacional de Vigilância Sanitária, e dá outras providências. Diário Oficial da União, Brasília, DF, 27 jan. 1999. p. 1. Disponível em: <https://bit.ly/2XYtWRC>. Acesso em: 11 maio 2018.

CELLARD, A. A análise documental. In: POUPART, J. et al. A pesquisa qualitativa: enfoques epistemológicos e metodológicos. Petrópolis: Vozes, 2008. p. 295-316.

DRAGANOV, P. B.; SANNA, M. C. Desenhos arquitetônicos de hospitais descritos no livro "Notes on Hospitals" de Florence Nightingale. História da Enfermagem, Brasília, DF, v. 8, n. 2, p. 94-105, 2017. Disponível em: <https://bit. ly/35XDwbY>. Acesso em: 21 maio 2018.

ESCOREL, S. História da política de saúde no Brasil: 1964 a 1990: do golpe militar à reforma sanitária. In: GIOVANELLA, L. et al. (Org.). Políticas e sistema de saúde no Brasil. Rio de Janeiro: Fiocruz, 20o8. p. 385-434.

FOUCAULT, M. Microfísica do poder. Rio de Janeiro: Graal, 2012.

\section{HOSPITAL SANTA CATARINA. [Projetos} arquitetônicos do Hospital Santa Catarina, Avenida Paulista, 20o]. 1974-2002. 14 f. Plantas diversas. Originais em papel vegetal.

LE GOFF, J. História e memória. Campinas: Unicamp, 1996.

LIMEIRA, F. M. Arquitetura e integralidade em saúde: uma análise do sistema normativos para estabelecimentos assistenciais de saúde. 2006. Dissertação (Mestrado em Arquitetura e Urbanismo) - Universidade de Brasília, Brasília, DF, 2006. 
OGUISSO, T.; SCHIMIDT, M. J. O exercício da enfermagem: uma abordagem ético-legal. Rio de Janeiro: Guanabara Koogan, 2017.

PAIVA, C. H. A.; TEIXEIRA, L. A. Reforma sanitária e a criação do Sistema Único de Saúde: notas sobre contextos e autores. História, Ciências, Saúde - Manguinhos, Rio de Janeiro, v. 21, n. 1, p. 15-35, 2014.

PASTRO, C. Hospital Santa Catarina: 1906-20o6. São Paulo: Grafa, 2006.

PEREIRA, D. H. M. A história da reprodução humana no Brasil. Femina, Rio de Janeiro, v. 39, n. 2, p. 59-64, 2011.

PIRES, D. A enfermagem enquanto disciplina, profissão e trabalho. Revista Brasileira de Enfermagem, Brasília, DF, v. 62, n. 5, p. 739-744, 2009.

SANNA, M. C. Histórias de enfermeiras gerentes: subsídios para a compreensão de um modeloreferência de organização de serviços de enfermagem no período de 1950 a 1980. Rio de Janeiro: Escola Anna Nery, 2002.

SILVA, J. M. C. Projeto é documento: a experiência de pesquisa na coleção Jacques Pilon da Biblioteca da FAU-USP. In: ENCONTRO DA ASSOCIAÇÃO NACIONAL DE PESQUISA E PÓS-GRADUAÇÃO EM ARQUITETURA E URBANISMO, 3., 2014, São Paulo. Anais... São Paulo: Universidade Presbiteriana Mackenzie; Campinas: Pontifícia Universidade Católica de Campinas, 2014. Disponível em: <https://bit.ly/2XYuOFS>. Acesso em: 5 jan. 2021.

TEIXEIRA, S. M. F. Reflexões teóricas sobre democracia e reforma sanitária. In: TEIXEIRA, S. M. F. Reforma sanitária: em busca de uma teoria. São Paulo: Cortez; Rio de Janeiro: Abrasco, 1989. p.17-46.

VIETTA, E. P. et al. Depoimentos de enfermeiras hospitalares da década de 6o: subsídios para a compreensão da enfermagem atual. Revista Latino-Americana de Enfermagem, Ribeirão Preto, v. 4, n. 2, p. 23-39, 1996.

\section{Contribuição dos autores}

Draganov concebeu o projeto, analisou e interpretou os dados e redigiu o artigo. Sanna executou a revisão crítica do conteúdo intelectual. Ambas as autoras aprovaram a versão final a ser publicada.

Recebido: $11 / 06 / 2020$

Aprovado: $11 / 09 / 2020$ 